\title{
An integrative therapeutic approach to elephantiasis nostras verrucosa: A case report
}

\author{
LAWRENCE CHUKWUDI NWABUDIKE ${ }^{1,2^{*}}$, OLIMPIA BUZIA ${ }^{2,3 *}$, \\ ALINA MIHAELA ELISEI $^{3,4}$ and ALIN LAURENTIU TATU ${ }^{2,4-6}$
}

\begin{abstract}
${ }^{1}$ Outpatient Dermatology Department, 'Dr. N.C. Paulescu' National Institute of Metabolic Disease, Nutrition and Diabetes, 020475 Bucharest; ${ }^{2}$ Multidisciplinary Integrated Center of

Dermatological Interface Research (MIC-DIR), 800010 Galati; ${ }^{3}$ Department of Pharmaceutical Sciences,

4Medical and Pharmaceutical Research Unit/Competitive, Interdisciplinary Research Integrated Platform 'Dunărea de Jos', ReForm-UDJG and ${ }^{5}$ Clinical Department-Dermatology, Faculty of Medicine and Pharmacy, 'Dunărea de Jos' University, 800008 Galati; ${ }^{6}$ Dermatology Department, 'Sf. Parascheva’ Infectious Diseases Clinical Hospital, 800003 Galati, Romania
\end{abstract}

Received September 3, 2021; Accepted October 5, 2021

DOI: $10.3892 /$ etm.2022.11218

\begin{abstract}
Elephantiasis nostras is a chronic disorder that is difficult to treat. It is characterized by marked lymphedema, associated with hyperkeratosis, ulceration, deep skin folds and a cobblestone appearance of the skin. Causes include parasitic and bacterial infections, neoplasia and obesity, but numerous cases have uncertain aetiology. Treatment includes surgery and medication, which are associated with variable results. In the present study, a 72-year old female with renal insufficiency presented with leg enlargement of 3-4 years duration, which rendered her housebound. Examination showed massive lower limb enlargement, with typical cobblestone appearance. She was on furoseminde $80 \mathrm{mg} /$ day. A diagnosis of elephantiasis nostras was made. Then, she was treated with increased furosemide from 80 to $120 \mathrm{mg}$ daily and homeopathic Apocynum cannabinum, $\mathrm{CH} 30$ potency, t.d.s. Unavailability of corresponding fit excluded the use of compressive stockings. The patient remitted over 18 months, with limb diameters dropping from 68/46 cm (right mid-calf/ ankle) and $67 / 43 \mathrm{~cm}$ (left mid-calf/ankle) to $64 / 43 \mathrm{~cm}$
\end{abstract}

Correspondence to: Dr Lawrence Chukwudi Nwabudike, Outpatient Dermatology Department, 'Dr. N.C. Paulescu' National Institute of Metabolic Disease, Nutrition and Diabetes, Str. Ion Movila 5-7, 020475 Bucharest, Romania

E-mail: chukwudi.nwabudike@live.com

Dr Alina Mihaela Elisei, Department of Pharmaceutical Sciences, Faculty of Medicine and Pharmacy, 'Dunărea de Jos' University, Str. Al. I. Cuza 35, 800008 Galați, Romania

E-mail: a_elisei@yahoo.com

*Contributed equally

Key words: elephantiasis nostras, lymphedema, homeopathy, integrative medicine, furosemide, Apocynum cannabinum (right mid-calf/ankle) and 64.5/45 cm (left mid-calf/ankle) at 6 months, $63 / 42 \mathrm{~cm}$ (right mid-calf/ankle) and 65/41 cm (left mid-calf/ankle) at 12 months, and $46 / 35 \mathrm{~cm}$ (right mid-calf/ ankle) and 48/36 cm (left mid-calf/ankle) at 18 months, with improvement of skin appearance. Elephantiasis nostras is not spontaneously remitting. In this resource-limited setting, furosemide combined with homeopathic Apocynum cannabinum has proved valuable and may be used for similar cases.

\section{Introduction}

Elephantiasis nostras refers to severe lymphedema and is often associated with characteristic skin changes, such as ulceration, deep folds, hyperkeratosis and a cobblestone appearance $(1,2)$. This latter feature is likely to be responsible for the designation 'verrucosa' sometimes used in the name of this disorder. Elephantiasis nostras is typically difficult to treat and a variety of modalities, including compressive stockings, surgery, manual lymph drainage, pressure devices and drug therapy have been tried (3-6). Since lymphedema implies an accumulation of protein-rich fluid, as opposed to simple fluid accumulation of edema, diuretics tend to be of little use (7).

Apocynum cannabinum, also popularly known as dogbane/ indian hemp, is a poisonous herb that has been used by native tribes for a variety of purposes and is also used in homeopathy for the treatment of edema (8-10).

The present study reported a case of elephantiasis nostras of 3-4 years duration treated successfully with combined furosemide and homeopathic Apocynum cannabinum.

\section{Case report}

A 72-year old woman presented with a 3 to 4-year history of massive pedal edema. It had begun on the right leg progressing afterwards to involve the left leg. There was no history of infections, cardiac, renal, thyroid or hepatic disease elicited.

Subsequent blood tests revealed slight anemia, renal impairment with hypoalbuminemia and raised creatinine and 
uric acid. The patient was housebound and cared for by her sister. Thus, more comprehensive tests were not possible. She had been on furosemide $80 \mathrm{mg} / \mathrm{day}$, with no improvement of her elephantiasis nostras.

Examination showed marked elephantiasis with limb diameters of $68 / 46 \mathrm{~cm}$ (right mid-calf/ankle) and $67 / 43 \mathrm{~cm}$ (left mid-calf/ankle). There was also marked erythema, oozing and excoriation of the legs with deep folds and creases. Photographic documentation was carried out with informed consent from the patient (Figs. 1 and 2).

The patient was prescribed $120 \mathrm{mg}$ of furosemide daily and the homeopathic medicine Apocynum cannabinum at $\mathrm{CH} 30$ potency, t.d.s., as well as daily povidone iodine dressing for her legs. Compressive stockings could not be used due to unavailability of a corresponding fit.

The oozing and erythema gradually reduced and her leg diameter decreased (Fig. 3).

Table I presents the gradual decrease in limb diameter at $\sim 8$-week intervals. At 12 months of treatment, limb diameters were $63 / 42 \mathrm{~cm}$ for right mid-calf/ankle and $65 / 41 \mathrm{~cm}$ for left mid-calf/ankle with minimal oozing. At 18 months of treatment, leg diameters were $46 / 35 \mathrm{~cm}$ for right and $48 / 36 \mathrm{~cm}$ for left mid-calf/ankle areas, with improvement in skin appearance (Fig. 4).

The patient was subsequently able to be ambulatory and to take short walks around her apartment block or up and down the communal stairs, as the weather permitted.

An increase in limb diameters was observed at 23 months (Table I), which followed the death of her sister who was taking care of her. The patient had been brought for this visit by her nephew, became lost to follow up after this visit and was later reported as deceased.

\section{Discussion}

In this difficult-to-treat disorder, elephantiasis nostras, which is not known for spontaneous remission, the combination of furosemide $120 \mathrm{mg} / \mathrm{day}$ and Apocynum cannabinum at $\mathrm{CH} 30$, t.d.s. was very valuable in the treatment of our patient. Patient's improvement was slow and the reduction in limb size over time was gradual and incremental (Table I), each $\mathrm{cm}$ reduction in diameter implying a large reduction in edema, which could be observed clinically as significant improvement over the entire limb. The improvement of the appearance of the limbs, such as the disappearance of the cobblestone appearance and the deep folds, as well as the healing of the excoriations and oozing, led to improvement of the quality of life of the patient.

Elephantiasis nostras is a chronic condition characterized by lymphedema and that has numerous possible causes $(1,2)$. Many types of treatments have been tried, including benzopyrones, retinoids, selenium, surgery, laser therapy, manual therapy, and compressive therapy (3-6), which have varying effects. Stem cell treatment has also shown promising results and diuretics are not considered effective $(1,7)$. Treatment of this disease aims to reduce disability, thus alleviating the psychological distress associated with the condition, and to manage comorbidities $(1,7)$.

Elephantiasis nostras is not usually responsive to diuretic therapy as lymphedema, and unlike simple edema, it is

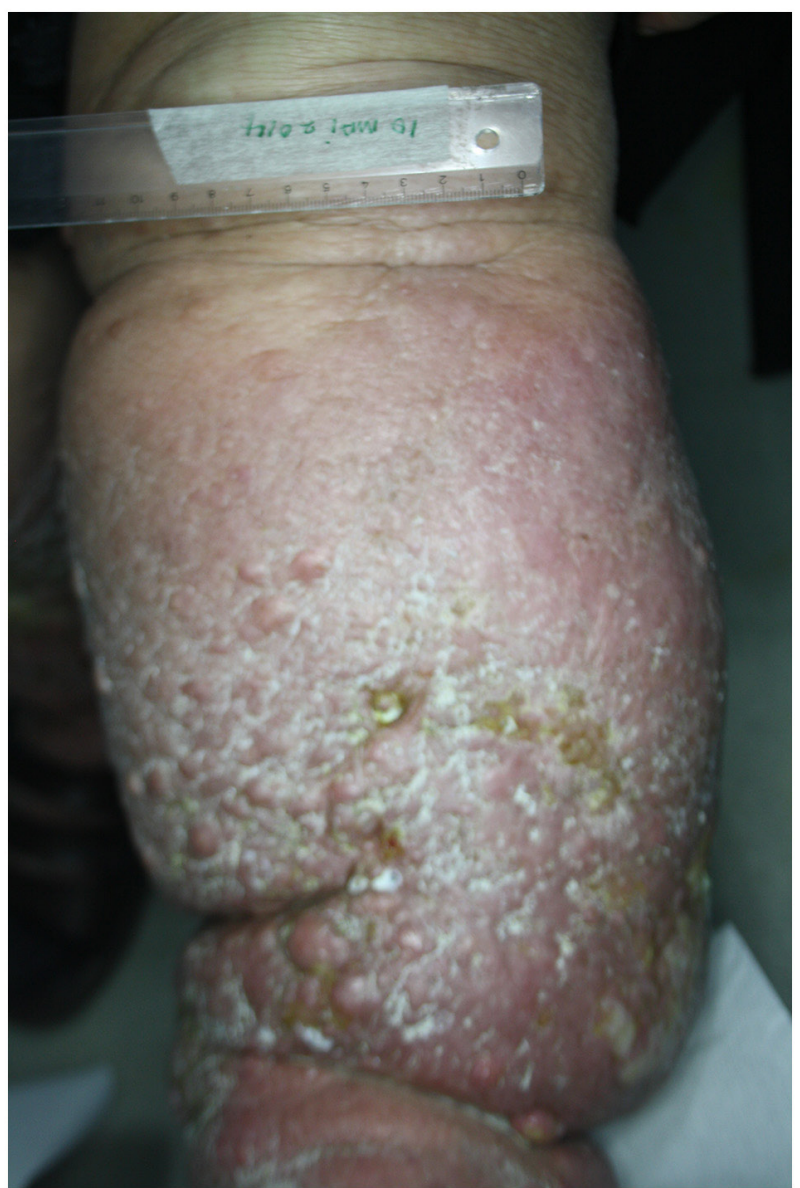

Figure 1. Image of the right leg, showing massive edema with deep folds, exudation, erythema and cobblestone appearance, more prominent than the left leg.

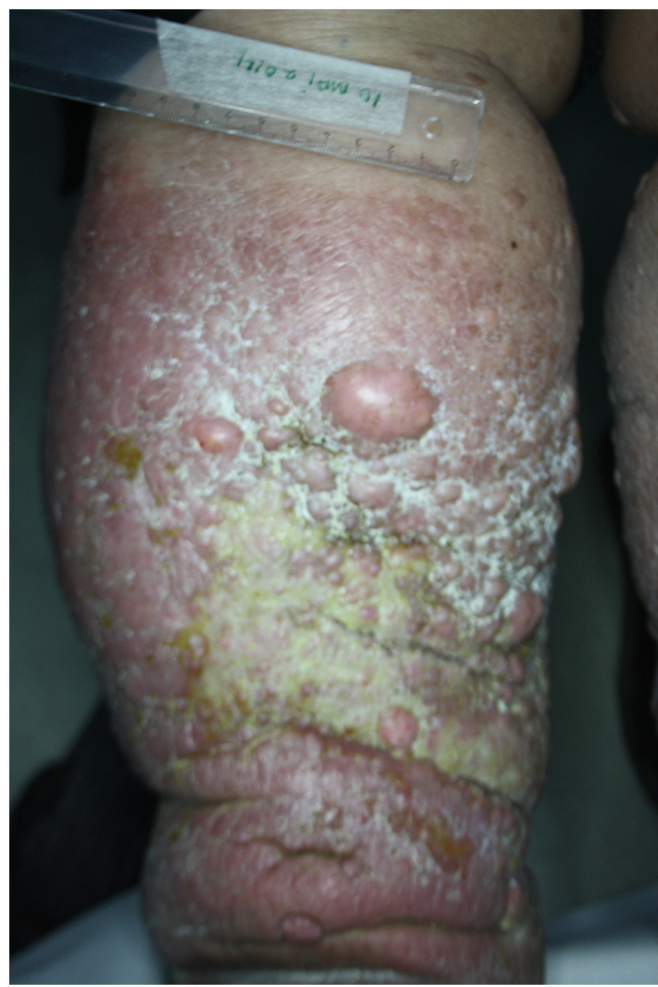

Figure 2. Image of the left leg, presenting massive edema with deep folds, exudation, erythema and cobblestone appearance. 
Table I. Changes in leg diameters in the patient treated with furosemide combined with homeopathic Apocynum cannabinum over time.

\begin{tabular}{lcccc}
\hline & \multicolumn{3}{c}{ Diameter, cm } \\
\cline { 2 - 4 } Date & Left mid-leg & Left ankle & Right mid-leg & Right ankle \\
\hline May 10th, 2014 & 67.0 & 43.0 & 68.0 & 46.0 \\
June 13th, 2014 & 66.0 & 46.0 & 67.0 & 46.0 \\
July 26th, 2014 & 67.5 & 45.0 & 70.0 & 47.0 \\
September 13th, 2014 & 64.5 & 46.0 & 67.0 & 46.0 \\
October 4th, 2014 & 65.0 & 43.0 & 65.5 & 45.5 \\
November 29th, 2014 & 64.0 & 43.0 & 64.5 & 45.0 \\
February 7th, 2015 & 63.5 & 38.5 & 63.0 & 42.0 \\
April 4th, 2015 & 62.0 & 41.0 & 62.0 & 42.0 \\
Mat 16th, 2015 & 65.0 & 41.0 & 63.0 & 42.0 \\
July 17th, 2015 & - & - & - & - \\
September 12th, 2015 & 50.0 & 38.0 & 48.0 & 38.0 \\
November 7th, 2015 & 48.0 & 36.0 & 46.0 & 35.0 \\
January 8th, 2016 & 48.0 & 36.0 & 47.5 & 39.0 \\
April 12th, 2016 & 52.0 & 41.0 & 47.0 & 39.0 \\
\hline
\end{tabular}

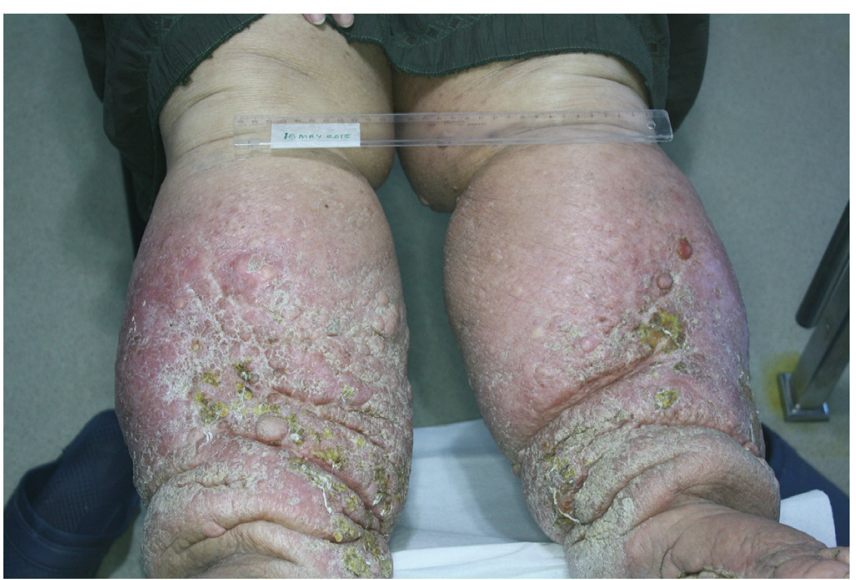

Figure 3. Images of both legs with diminished edema, erythema, exudation and shallower skin folds.

characterized by a high amount of proteins in the extracellular space, due to impairment of lymphatic function $(3,7,11)$ The patient from the present study was already on furosemide and it was thought that no benefit would be gained from its removal, but that there might be some gain from an increased dosage (bearing in mind the patient's underlying renal insufficiency), together with the use of homeopathic Appocynum cannabinum. Diuretics, aside from being apparently futile in this disorder, might sometimes predispose to non-melanoma skin cancer, like in the case of hydrochlorothiazide (12).

Homeopathic medicines consist of highly diluted substances, which are thought to work by stimulating the body's innate capacity for regeneration. Homeopathy is a therapeutic system established by the German physician Samuel Christian Hahnemann (1755-1843). It is based on a principle earlier advocated by Hippocrates. Although there

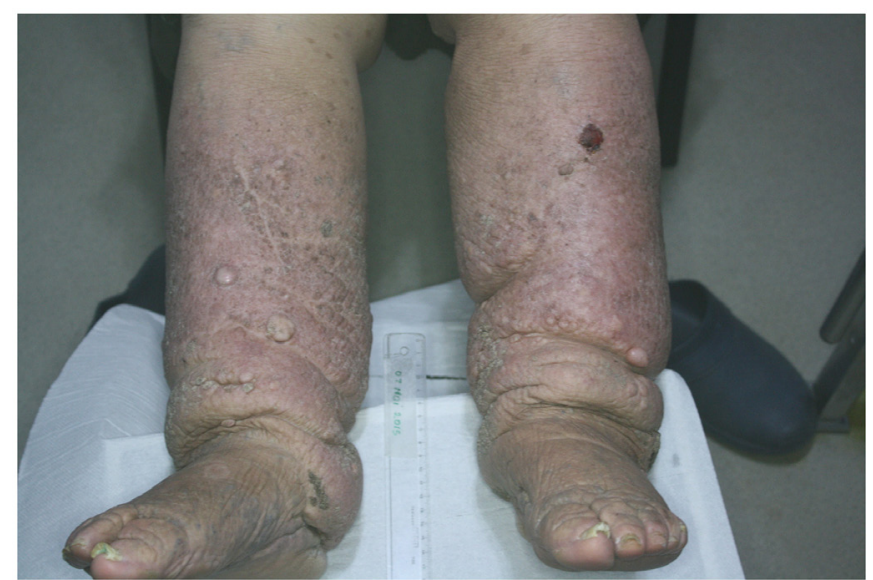

Figure 4. Images of both legs with minimal edema, folds, cobblestone appearance and erythema ameliorated.

is not yet certainty about the actual mechanism of action of homeopathy, research by the Nobel Prize laureate Professor Luc Montagner (13) suggests that highly diluted solutions, such as those used in homeopathy, might emit electromagnetic signals similar to those of the original solute. Other studies have reported that highly diluted solutions may induce the formation of nanomolecules, which can mimic the action of the original solute (14). These nanomolecules may further influence physiological processes in the human body (14). Previous case reports and case series suggested that homeopathy could be useful in a wide variety of cutaneous disorders, including acne $(15,16)$, psoriasis $(17)$, recalcitrant generalized lichen planus (18) and cutaneous lymphoma (19).

In summary, elephantiasis nostras is a severe form of secondary lymphedema that does not often spontaneously remit. A variety of treatments, including benzopyrones, 
retinoids, surgery and compression are available. These treatments should be tailored to the cause, if this one has been found, although they could potentially induce some side-effects. Elephantiasis nostras usually requires a multidisciplinary team approach and good collaboration between clinicians. Elephantiasis nostras is not thought to be responsive to diuretic therapy, as the disorder is due to accumulation of a protein-rich exudate. The patient from the present study responded well to a combination of a homeopathic medicine and high-dose furosemide. It is unlikely that any placebo effect would play a significant role in the treatment of this case.

The findings from this case report may be an opportunity to further research into the role of integrative therapeutic approaches (high-dose furosemide and homeopathy) in the therapy of lymphedema.

\section{Acknowledgements}

The present work was academically supported by the 'Dunarea de Jos' University of Galati, Romania, through the research center - Multidisciplinary Integrated Center of Dermatological Interface Research (MIC-DIR; Galati, Romania).

\section{Funding}

The article processing charge (APC) was funded by 'Dunarea de Jos' University, Galati, Romania.

\section{Availability of data and materials}

Not applicable.

\section{Authors' contributions}

LN collected the data and conceived the study. LN, OB, AE and AT contributed to the drafting, writing and final correction of the manuscript. All authors read and approved the final manuscript.

\section{Ethics approval and consent to participate}

The study was approved by the Ethics committee of Dr Nwabudike Cabinet Medical (nr 01/06 Jan 2020). The patient provided informed consent.

\section{Patient consent for publication}

The patient consented to the use of her data in the present study.

\section{Competing interests}

The authors declare that they have no competing interests.

\section{References}

1. Liaw FY, Huang CF, Wu YC and Wu BY: Elephantiasis nostras verrucosa: Swelling with verrucose appearance of lower limbs. Can Fam Physician 58: e551-e553, 2012.

2. Molodoi AD, Dimitriu A, Andronic CD, Stoleriu G, Bădescu A, Boda D and Branisteanu DE: Pyoderma vegetans developed on chronic leg ulcer. Rev Med Chir Soc Med Nat Iasi 119: 107-111, 2015.

3. Kerchner K, Fleischer A and Yosipovitch G: Lower-extremity lymphedema update: Pathophysiology, diagnosis, and treatment guidelines. J Am Acad Dermatol 59: 324-331, 2008.

4. Merchant SJ and Chen SL: Prevention and management of lymphedema after breast cancer treatment. Breast J 21: 276-284, 2015.

5. Casley-Smith JR and Casley-Smith JR: Modern treatment of lymphoedemas II. The benzopyrones. Australas J Dermatol 33: 69-74, 1992.

6. Bastein MR, Goldstein BG, Lesher JL Jr and Smith JG Jr: Treatment of lymphedema with a multicompartmental pneumatic compression device. J Am Acad Dermatol 20 (5 Pt 1): 853-854, 1989.

7. Schwartz RA and Kapila R: Lymphedema treatment and management, 2020. https://emedicine.medscape.com/ article/1087313-treatment. Accessed September 9, 2020.

8. Jänicke C, Grünwald J and Brendler T: Kanadischer Hanf. In: Apocynum cannabinum in Handbuch Phytotherapie. Wissenschaftliche Verlagsgesellschaft $\mathrm{mbH}$, Stuttgart, 2003 (In German).

9. No authors listed: Apocynum cannabinum in mitral disease. Hospital (Lond1886) 39: 6-7, 1905.

10. Murphy R: Apocynum cannabinum.In: Nature's Materia Medica, 2007 (Electronic edition, ReferenceWorks Software).

11. Burckhart CN, Adigun C and Burton CS: Cutaneous changes in venous and lymphatic insufficiency. In: Fitzpatrick's Dermatology in General Medicine. Wolff K, Goldsmith LA, Katz SI, Gilchrest BA, Paller AS and Leffell D (eds). 8th edition. McGraw Hill, New York, NY, 2008.

12. Tatu AL, Ciobotaru OR, Miulescu M, Buzia OD, Elisei AH, Mardarea N, Diaconu C, Robu S and Nwabudike LC: Hydrochlorothiazide: Chemical structure, therapeutic, phototoxic and carcinogenetic effects in dermatology. Rev Chim (Bucharest) 69: 2110-2114, 2018.

13. Montagnier L, Aïssa J, Ferris S, Montagnier JL and Lavallée C: Electromagnetic signals are produced by aqueous nanostructures derived from bacterial DNA sequences. Interdiscip Sci 1: 81-90, 2009.

14. Chikramane PS, Suresh AK, Bellare JR and Kane SG: Extreme homeopathic dilutions retain starting materials: A nanoparticulate perspective. Homeopathy 99: 231-242, 2010.

15. Nwabudike LC: Individualised homeopathic treatment of acne-an analysis of 83 patients. Homeopathy 110: 271-276, 2021. doi: $10.1055 / \mathrm{s}-0041-1728666$.

16. Nwabudike LC: Case reports of acne and homeopathy. Complement Med Res 25: 52-55, 2018.

17. Witt CM, Lüdtke R and Willich SN: Homeopathic treatment of patients with psoriasis-a prospective observational study with 2 years follow-up. J Eur Acad Dermatol Venereol 23: 538-543, 2009.

18. Nwabudike LC, Miulescu M and Tatu AL: Case series of an alternative therapy for generalised lichen planus: Four case studies. Exp Ther Med 18: 943-948, 2019.

19. Nwabudike LC: Homeopathy as therapy for mycosis fungoides: Case reports of three patients. Homeopathy 108: 277-284, 2019.

This work is licensed under a Creative Commons Attribution-NonCommercial-NoDerivatives 4.0 International (CC BY-NC-ND 4.0) License. 